\title{
IDENTIFICATION OF 33 CHINESE RHODODENDRON SPECIES USING MATK SEQUENCES AND AFLP DATA
}

Jochen Dendauw, Jan De Riek, Marc De Loose and Erik Van Bockstaele

Department of Plant Genetics and Breeding

Caritasstraat 21

9090 Melle

Belgium

j.deriek@clo.fgov.be

Keywords: matK, AFLP, Rhododendron, pot azalea, genetic diversity

\section{$\underline{\text { Abstract }}$}

The current assortment of pot azalea (Rhododendron simsii hybrids) has been created from a relatively narrow basis of collectors material brought from the far east. $R$. simsii, the main ancestor, originates from hilly areas in China, Thailand, Laos and Burma. However several other species from the Tsutsusi subgenus, from South-Asia and Japan might have contributed e.g. $R$. indicum, $R$. mucronatum, and $R$. scabrum. From the Kunming Institute of Botany (China) 33 seed lots from natural populations in mountain area's with an altitude ranging from 250 to $3500 \mathrm{~m}$ were obtained. The majority of these Rhododendron species belong to the Tsutsusi subgenus; 8 are $R$. simsii. Per population 10 plants were analysed by AFLP using 3 primer combinations. They were compared to the breeders pot azalea genepool (70 plants, some with common pedigree and bud sports). AFLP was performed using the commercially available kit for fluorescent fragment detection on an ABI Prism 377 DNA Sequencer. The genetic diversity of the different gene pools was analysed by comparison of the marker frequencies, by calculating similarity indices, by multivariate analysis and AMOVA. Small differences within populations were observed. Large variation was observed within the $R$. simsii species and between the different species from the Tsutsusi subgenus. The pot azalea genepool was clearly distinguishable from the Chinese accessions. On dendrograms it was more closely clustered to $R$. simsii and $R$. mucronatum than to less related species.For mat $\mathrm{K}$ sequencing a subset of plants from the Chinese accessions was selected and compared to examples from the breeders pot azalea genepool. For amplification and sequencing 4 primer couples were applied that covered in total a DNA sequence of $2529 \mathrm{bp}$. Multiple alignment from all sequences was used as template for a phylogenetic analysis. One outgroup was defined for rooted tree construction. The dataset was analysed in three ways: Neighbour Joining based clustering, parsimony and maximum likelihood analysis. The topology of the trees achieved by AFLP and matK analysis were compared. Several corresponding clusters could be identified, showing the complementarities of both approaches.

\author{
Abbreviations

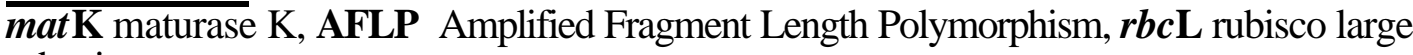 \\ subunit
}

\section{$\underline{\text { 1. Introduction }}$}

The genus Rhododendron is well known for the beauty and diversity of floral and vegetative form of its more than 1000 species. Because of the many species within this genus, during history taxonomists have made several classifications mainly based on morphological data (i.e. flowers, leafs, hairs, etc.). Morphological data are relatively easy to obtain, but only a small number of characters can be evaluated. An alternative for this 
reason classification may be based on molecular data. Molecular data provide the possibility to study a tremendous number of genetic loci in three distinct genomes (nuclear, mitochondrial, and chloroplast DNA). In plant systematics the chloroplast genome has proven to be very informative. Two of the genes that have been useful in constructing evolutionary trees in the Ericaceae are $r b c \mathrm{~L}$ (rubisco large subunit) and $m a t \mathrm{~K}$ (maturase $\mathrm{K}$ ). The $m a t \mathrm{~K}$ is known to evolve approximately three times faster than $r b c \mathrm{~L}$, and is therefore a powerful tool for phylogenetic reconstruction within angiosperm families and genera (Hilu and Liang, 1997). On the other hand, the use of molecular markers can be very effective to study within species diversity or the relationships between closely related species.

\section{Material and methods}

\subsection{Plant material}

From the Kunming Institute in China we received seed lots from several locations (Table 1) within the provinces Yunnan, Hunan, Fujian and Jiangxi, from a range of altitudes. After sowing and growing the plants in the greenhouse, young leafs were harvested, lyophilised and stored in $-80{ }^{\circ} \mathrm{C}$ until use. For the other plants (mainly $R$. simsii hybrids from the DvP-genepool ) young leaf material was directly available.

\subsection{DNA isolation}

From the young leafs total DNA was extracted using a two step protocol, a modification of the method described by Greenwood et al. (1989).

\subsection{AFLP reactions and PAGE}

AFLP reactions were run on an ABI Prism 377 DNA Sequencer using the commercially available kit for fluorescent fragment detection (AFLP Amplification Core Mix Module (P/N 402005 from Applied Biosystems). Selective amplification was done using 3 fluorescent-labelled EcoRI/MseI primer combinations with 6 selective bases : EcoRI-ACT / MseI-CTA, EcoRI-ACT/MseI-CAT and EcoRI-AAG/MseI-CTA (De Riek et al., 1999).

\section{4. matK amplification and sequencing}

A specific $\mathrm{PCR}$ to amplify the mat $\mathrm{K}$ gene was performed on the 33 Chinese Rhododendron species. For this purpose 4 primer couples were used (Kurashige et al., 1998) (Table 2 and 3; Fig. 1). The amplified PCR fragments were directly used for sequencing, using the PCR primers as sequencing primers (forward and reverse). Dideoxy sequencing was done using the Big Dyes Chemistry on a ABI Prism 377 DNA sequencer (Applied Biosystems). The obtained sequences from the several contigs were assembled using the Auto Assembler software (Applied Biosystems).

\subsection{Data analysis}

For the scoring of the AFLP fingerprints, the settings for semi-automated scoring of fluorescent reactions defined by De Riek et al. (1999) were applied. Statistical analysis

was based on 179 scored AFLP-markers. Calculations of similarity coefficients, construction of dendrograms (UPGMA) and principal co-ordinates analysis were performed by the modules SIMIL, CLUSTER and PCOORD of the "R package" (Legendre and Vaudor, 1991).

Alignment of the mat $\mathrm{K}$ sequences prior to parsimony analysis was performed by ClustalW 1.81 and a alignment control was done with GeneDoc 2.3. Parsimony analysis 
was done with PAUP (Phylogenetic Analysis Using Parsimony), version 4B.8 (Swofford, 1993). Trees were obtained using $100 \mathrm{X}$ bootstrapping, stepwise addition and tree bisection recognition as branch swapping algorithm.

\section{Results}

\subsection{AFLP fingerprinting}

To evaluate the genetic conformity between and within populations and the gene pool collection used in the breeding program, two approaches were applied : ordination analysis (clustering and principal co-ordinate analysis) and analysis of molecular variance (not reported here). Both type of analysis take a similarity or distance matrix as an input.

A pair wise similarity matrix was calculated on the basis of the frequencies of the markers in each population (Euclidean distance). In Fig.2, a cladogram is showing the genetic similarity between assayed populations. The Belgian pot azaleas, Hirado and Kurume azaleas were considered to be separate and well defined populations to be able to calculate marker frequencies. Bootstrap analysis was used to evaluate the reproducibility of the obtained groupings. Being supported by high bootstrap values, three major clusters and some outlying species can be distinguished. The first group contains $R$. florulentum, $R$. rufulum, $R$. seniavinii and two populations of $R$. rivulare. All these species belong to the Tsutsusi section of the Tsutsusi subgenus. AFLP fingerprints for $R$. florulentum and $R$. rufulum appeared to be very alike. These species are also phenotypically very similar; taxonomic difference is based on the size of the flowers. The second group solely holds $R$. simsii populations clustered with its subspecies mesembrinum. The third group consists of the in China free proliferating cultivated species $R$. x pulchrum and $R$. mucronatum and the different groups of cultivated azalea hybrids. The remaining species ( $R$. racemosum, $R$. yunnanense and $R$. mariesii) are clearly separated based on AFLP data.

\subsection{Phylogenetic analysis based on matK sequencing}

Phylogenetic analysis based on the mat $\mathrm{K}$ sequences was used to confirm the taxonomic position of the different species of the Tsutsusi subgenus. For that purpose, some extra species belonging to the subgenera Hymenanthes and Rhododendron were also analysed.

After sequencing and alignment of the different contigs a fragment of 2529 bp long was obtained covering mat $\mathrm{K}$ and its flanking $\operatorname{trn} \mathrm{K}$ sequences. For the analysis using PAUP, from the 2529 characters, 2438 characters were constant, 30 characters were variable and parsimony uninformative, 61 characters were variable and parsimony informative. Trees were generated using 100 resampled bootstrap datasets, stepwise addition and tree bisection recognition as branch swapping algorithm. The nodes that separated the different subgenera and sections all received high bootstrap values. In Fig.3, a parsimony cladogram is showing the genetic similarity between the assayed Chinese Rhododendron species and some $R$. simsii hybrids.

Five major clusters can be distinguished. The first group contains $R$. mariesii and $R$. farerrae, which was used as an outgroup species to root the dendrogram. Both species belong to the section Brachycalyx from the subgenus Tsutsusi. The second cluster contains $R$. yunnanense, $R$. spiciferum, $R$. x duclouxii, and two populations of $R$. racemosum. All these species belong to the subgenus Rhododendron. A third clusters contains $R$. fortunei, $R$. sinofalconeri, $R$. argyrophyllum, $R$. irroratum and two populations of $R$. decorum. All these species belong to the subgenus Hymenanthes. The fourth cluster contains $R$. florulentum, $R$. rufulum and two populations of $R$. rivulare. All these species belong to the subgenus Tsutsusi.

The last and largest cluster contains species all belonging to the section Tsutsusi, it can be divided in two subclusters. A first contains four $R$. simsii populations, two $R$. simsii var. mesembrinum populations, $R$. scabrum, R. kiusianum and the Kurume hybrid 
Cupido. A second subcluster contains five $R$. simsii hybrids, $R$. pulchrum, $R$. mucronatum, and $R$. scabrum.

\section{Discussion}

Computation of similarity or distance measures and ordination analysis allowed assessing genetic conformity and relatedness of the studied species and cultivated hybrids. The use of marker frequency data (Fig. 2) assures that all available genetic information is represented by the ordination. The mat $\mathrm{K}$ data confirm the previously obtained AFLP data. In general four distinct groups and some outlying species can be distinguished. The first group contains $R$. florulentum, $R$. rufulum, $R$. seniavinii (no mat $\mathrm{K}$ data) and two populations of $R$. ivvulare. All these species belong to the Tsutsusi section of the Tsutsusi subgenus. The marker data for $R$. florulentum and $R$. rufulum appeared to be very alike These species are also phenotypically very similar; taxonomic difference is based on the size of the flowers. A second group contains the $R$. simsii populations and cultivated $R$. simsii hybrids. $R$. simsii, generally considered to be the most important ancestor for pot azaleas due to type of flowers and the only ancestor exclusively distributed from China, seemed to be more apart. However, because a predominant number of $R$. simsii populations is included in this study, this might somewhat distort the AFLP ordination. The $R$. simsii populations are apart from the cultivated $R$. simsii hybrids; the latter are clustering with $R$. x pulchrum, $R$. scabrum, and $R$. mucronatum. This was confirmed by the mat $\mathrm{K}$ sequencing data. A third group consists of species belonging to subgenus Rhododendron, namely, $R$. yunnanense, $R$. racemosum, $R$. spiciferum (no AFLP data) and $R$. x duclouxii (no AFLP data). A last group consists of $R$. mariesii and $R$. farerrae (outgroup for mat $\mathrm{K}$ analysis) both belonging to the Section Brachycalyx of the Subgenus Tsutsusi.

Regarding the parentage of the cultivated hybrids, a closer clustering of $R . \mathrm{x}$ pulchrum and $R$. mucronatum with Hirado (AFLP data) and $R$. simsii hybrids or pot azalea (AFLP data and matK data) was observed (Fig $2 \& 3$ ). Kurume azaleas (AFLP and mat $\mathrm{K}$ data) were more distant (Fig. 2). $R$. x pulchrum is regarded to be a hybrid between $R$. indicum and $R$. mucronatum. Both species are also related to pot azaleas. According to Sweet, who described the species $R$. x pulchrum first, this taxon may be loosely grouped with the Azalea indica hybrids (a former erroneous name for $R$. simsii hybrids but also a term to describe the Satsuki azaleas) although it is not certain that both type of hybrids have the same parentage (Chamberlain and Rae, 1990). $R$. mucronatum has been cultivated at least for 300 years in Japan and China. The original wild form, native to Japan, is var. ripense with rose-pink flowers but widely cultivated together with var. mucronatum, an albino form. Hirado and pot azaleas share at least one important common ancestor, $R$. scabrum, originating from some small southern Japanese islands. 'Phoeniceum', one of the early crossing parents with supposed $R$. simsii plants from Sanghai that lead to the current $R$. simsii hybrids, is accepted to be a cross between $R$. mucronatum and R. scabrum (Galle, 1987).

\section{Acknowledgements}

The authors wish to thank Romain Uytterhaegen for his hands-on experience in azalea breeding and cultivation. We are especially indebted to the Chinese Kunming Institute for Botany with we established a good co-operation and exchange of material and trainees and to Dr. David Chamberlain of the Royal Botanical Garden in Edinburgh (UK) who unravelled the Tsutsusi taxonomy to us and was of great assistance in determination of the Chinese accessions. The Belgian Ministry of Small Enterprises Traders and Agriculture DG6 Research and Development, funded this research. 


\section{References}

Chamberlain D.F., and Rae S.J., 1990. A revision of Rhododendron IV Subgenus Tsutsusi. Edinburgh J. Bot. 47:89-200.

De Riek J., Dendauw J., Mertens M., De Loose M., Heursel J., and Van Bockstaele E., 1999. Validation of criteria for the selection of AFLP markers to assess the genetic variation of a breeders' collection of evergreen azaleas. Theor. Appl. Gen. 99:11551165.

Galle F., 1987. Azaleas. Timber Press Portland, Oregon pp. 519

Greenwood M.S., Hopper C.A., and Hutchison K.W., 1989. Maturation in Larch, Effect of age on shoot growth, foliar characteristics, and DNA methylation. Plant Physiol. 90:406-412.

Hilu K.W., and Liang H., 1997. The matK gene: sequence variation and application in plant systematics. American Journal of Botany 84(6):830-839.

Kurashige Y., Mine M., Kobayashi N., Handa T., Takayanagi K., and Yukawa T., 1998. Investigation of sectional relationships in the genus Rhododendron (Ericaceae) based on mat K sequences. J. Jpn. Bot. 73:143-154.

Legendre P., and Vaudor A., 1991. The R package: Multidimensional analysis, spatial analysis. Département de sciences biologiques, Université de Montréal, pp. 142.

Swofford D.L., 1993. PAUP: Phylogenetic Analysis Using Parsimony, Version 3.1. Computer program distributed by the Illinois Natural History Survey, Champaign, IL. 
Table 1. List of used species with there classification and origin.

\begin{tabular}{|c|c|c|}
\hline Species & Classification & Population \\
\hline $\begin{array}{l}\text { R. mariesii } \\
\text { R. farerrae }\end{array}$ & $\begin{array}{l}\text { Sect. Brachycalyx } \\
\text { Sect. Brachycalyx }\end{array}$ & Manshan Hunan \\
\hline $\begin{array}{l}R . \text { argyrophyllum } \\
R . \text { decorum }(a) \\
R . \text { decorum }(b) \\
R . \text { fortunei } \\
R . \text { irroratum } \\
R . \text { sinofalconeri }\end{array}$ & $\begin{array}{l}\text { Subg. Hymenanthes } \\
\text { Subg. Hymenanthes } \\
\text { Subg. Hymenanthes } \\
\text { Subg. Hymenanthes } \\
\text { Subg. Hymenanthes } \\
\text { Subg. Hymenanthes }\end{array}$ & \\
\hline $\begin{array}{l}R . x \text { duclouxii } \\
R . \text { racemosum }(a) \\
R . \text { racemosum }(b) \\
R . \text { spiciferum } \\
R . \text { yunnanense }\end{array}$ & $\begin{array}{l}\text { Subg. Rhododendron } \\
\text { Subg. Rhododendron } \\
\text { Subg. Rhododendron } \\
\text { Subg. Rhododendron } \\
\text { Subg. Rhododendron }\end{array}$ & $\begin{array}{l}\text { Yulong Caojian Yunnan } \\
\text { Huaping Yunnan }\end{array}$ \\
\hline $\begin{array}{l}R . \text { florulentum } \\
R . \text { kiusianum } \\
R . \text { mucronatum } \\
R . \text { x pulchrum } \\
R . \text { rivulare (a) } \\
R . \text { rivulare (b) } \\
R . \text { rufulum } \\
R . \text { scabrum } \\
R . \text { simsii (a) } \\
R . \text { simsii (b) } \\
R . \text { simsii (c) } \\
R . \text { simsii (d) } \\
R . \text { simsii (e) } \\
R . \text { simsii (f) } \\
R . \text { simsii var. mesembrinum (a) } \\
R . \text { simsii var. mesembrinum (b) } \\
R . \text { semavinii } \\
R . \text { simsii hybrids (pot azalea) } \\
\text { Kurume (winterhardy) } \\
\text { Hirado's (R. scabrum) } \\
\text { Kurume (not winterhardy) }\end{array}$ & $\begin{array}{l}\text { Sect. Tsutsusi } \\
\text { Sect. Tsutsusi } \\
\text { Sect. Tsutsusi } \\
\text { Sect. Tsutsusi } \\
\text { Sect. Tsutsusi } \\
\text { Sect. Tsutsusi } \\
\text { Sect. Tsutsusi } \\
\text { Sect. Tsutsusi } \\
\text { Sect. Tsutsusi } \\
\text { Sect. Tsutsusi } \\
\text { Sect. Tsutsusi } \\
\text { Sect. Tsutsusi } \\
\text { Sect. Tsutsusi } \\
\text { Sect. Tsutsusi } \\
\text { Sect. Tsutsusi } \\
\text { Sect. Tsutsusi } \\
\text { Sect. Tsutsusi } \\
\text { Sect. Tsutsusi }\end{array}$ & $\begin{array}{l}\text { Yanzhong Fujian } \\
\text { Lushan Jiangxi } \\
\text { Lushan Jiangxi } \\
\text { Daoxian Xiaojiangjiao Hunan } \\
\text { Manshan Hunan } \\
\text { Dongxiaobaitu Fujian } \\
\text { Yiliang Yunnan } \\
\text { Jianshui Yunnan } \\
\text { Daoxian Hunan } \\
\text { Xishan Yunnan } \\
\text { Kutiankang Fujian } \\
\text { Jiuyidianzhan Hunan } \\
\text { Daoxian Xiaojiangjiao Hunan } \\
\text { Lushan Jiangxi } \\
\text { Manshan Hunan } \\
\text { DvP genepool } \\
\text { DvP genepool } \\
\text { DvP genepool } \\
\text { DvP genepool }\end{array}$ \\
\hline
\end{tabular}


Table 2. Primer codes, primer sequence (IUPAC codes) and $\mathrm{T}_{\mathrm{m}}$ used for amplification of the mat $\mathrm{K}$ locus.

\begin{tabular}{llc}
\hline \multicolumn{1}{c}{ Primer } & \multicolumn{1}{c}{ 5' sequence 3' } & $\mathrm{T}_{\mathrm{m}}\left({ }^{\circ} \mathrm{C}\right)$ \\
\hline trnK 3914F & GGG GTT GCT AAC TCA ACG G & 56.4 \\
trnK 1 MF & GAT AAG TTT ACC GAG GTA GC & 47.6 \\
matK 462F & AAT ACC CTA YCC CRT YCA TC* & 48.9 \\
matK 3MF & GTG GTC TCA ACC AAG AAG G & 50.5 \\
matK 174R & CGA KTA ATT AAM CGT TTC AC* & 46.8 \\
matK 1MR & GTA GAA AAA ATC GTA ATA GC & 47.6 \\
matK 1848R & TAT CGA ACT TCT TAA TAG C & 40.9 \\
trnK 2R & AAC TAG TCG GAT GGA GTA G & 44.5 \\
\hline
\end{tabular}

* Degenerated primers for PCR

Table 3. The 4 primer pairs used (length of the expected amplicon).

\begin{tabular}{cllc}
\hline Primer pair & \multicolumn{1}{c}{ Forward primer } & \multicolumn{1}{c}{ Reverse primer } & Length Amplicon \\
\hline I & trnK 3914 F & mat K 174R & $\pm 920 \mathrm{bp}$ \\
II & trnK 1MF & matK 1MR & $\pm 720 \mathrm{bp}$ \\
III & matK 462 F & matK 1848R & $\pm 740 \mathrm{bp}$ \\
IV & matK 3MF & $\operatorname{trnK} 2 \mathrm{R}$ & $\pm 860 \mathrm{bp}$ \\
\hline
\end{tabular}

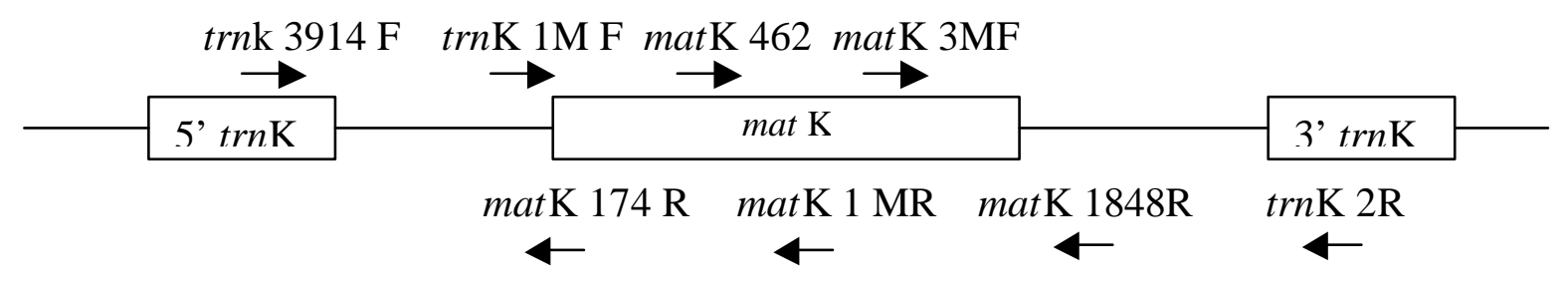

Figure 1. The mat $\mathrm{K}$ locus showing the position of the primers used for amplification of the partial sequences (Kurashige et al., 1998). 


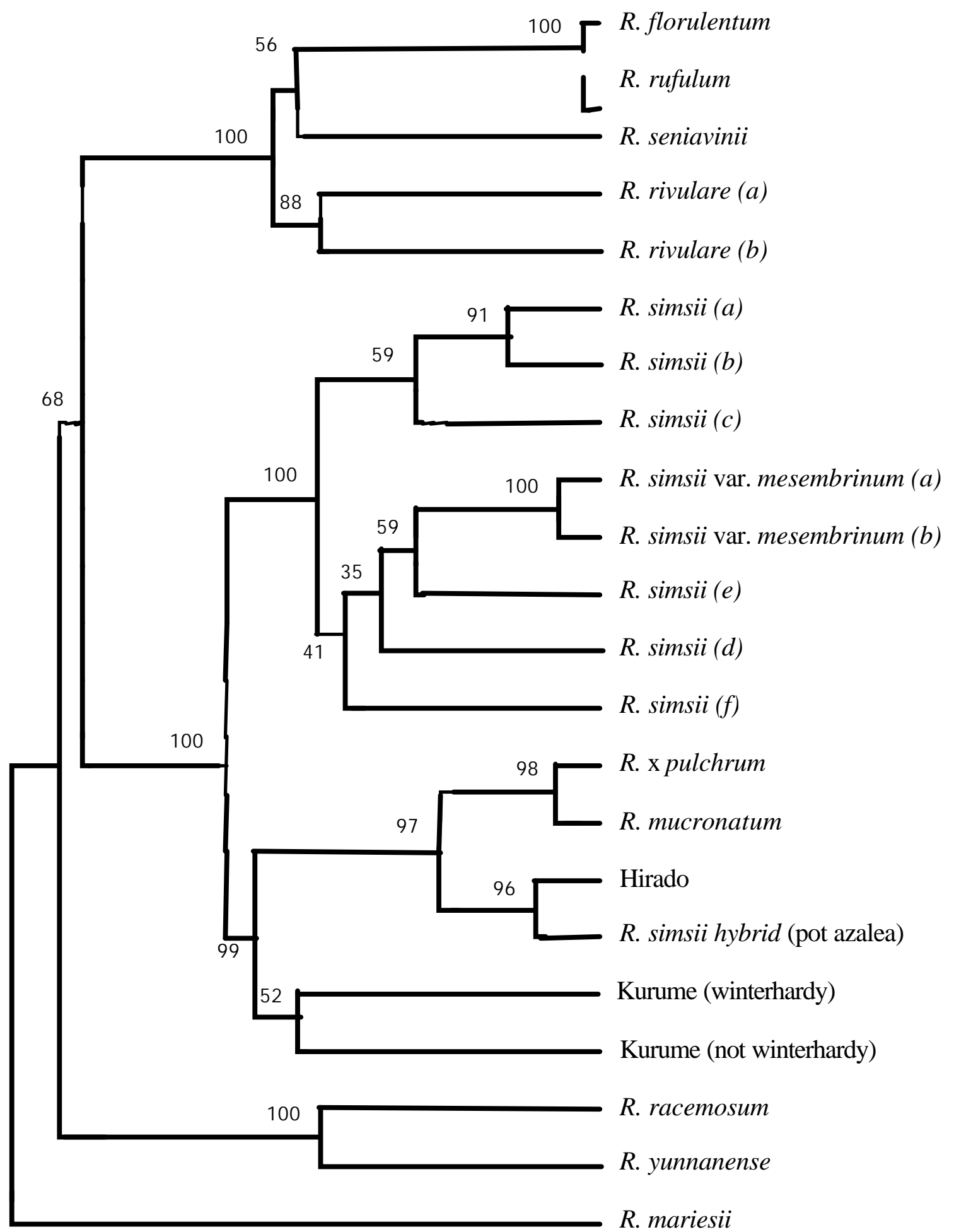

Figure 2. UPGMA cladogram based on Euclidean distance between different populations or groups for AFLP marker frequencies. 


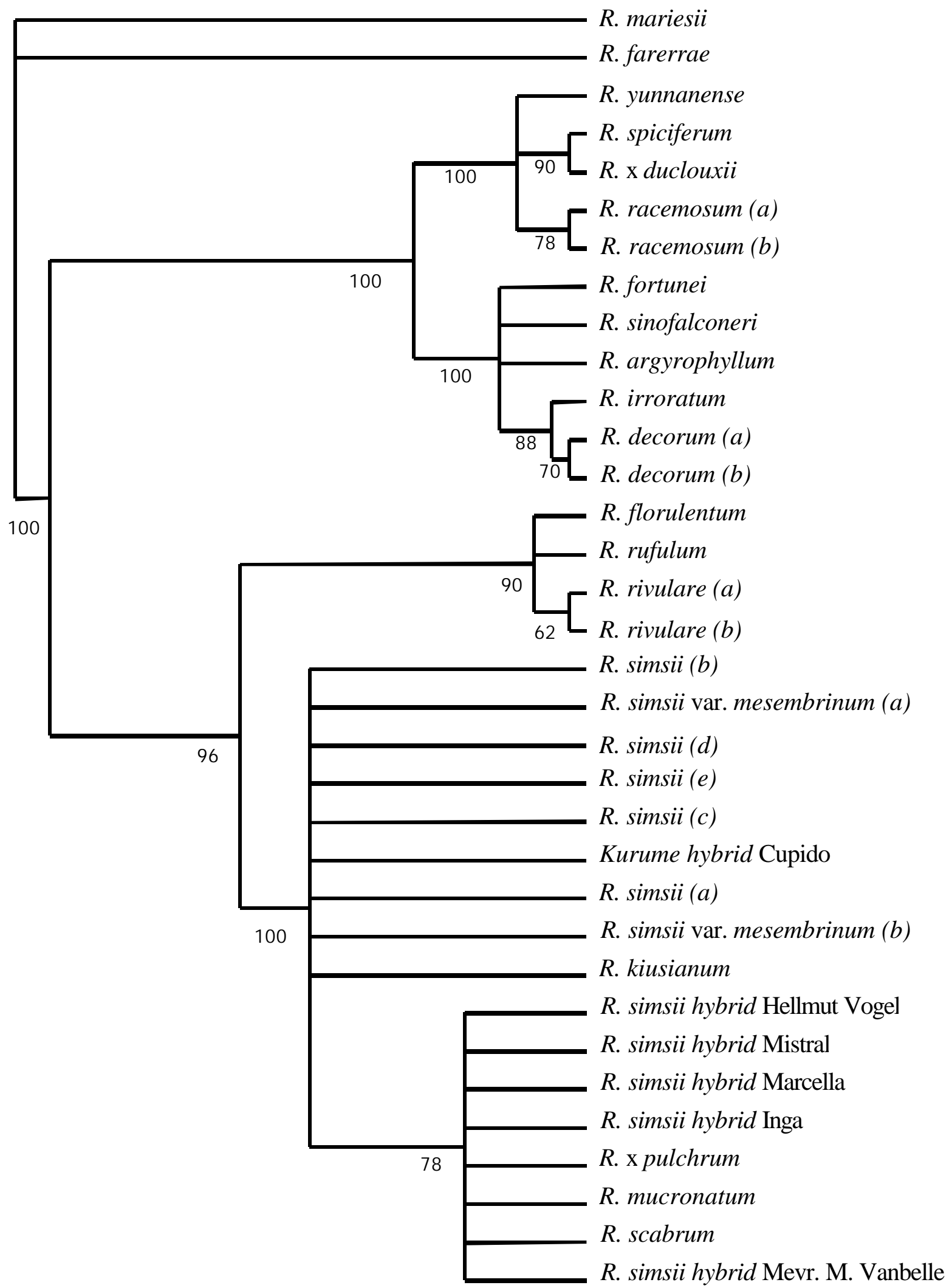

Figure 3. Consensus parsimony tree based on mat K data for a selection of Chinese Rhododendron species and cultivated $R$. simsii hybrids, length $=98$; consistency index (excluding uninformative characters) $=0.9403$; retention index $=0.9987$. 